\title{
Communication and Leadership Differences in Virtual Design Teams: Why some teams do better than others
}

\author{
Jerry Fjermestad $^{1}$ \& Rosalie J. Ocker ${ }^{2}$ \\ ${ }^{1}$ School of Management \\ New Jersey Institute of Technology \\ Newark, New Jersey 07102 \\ 973-596-3255 \\ fjermestad@adm.njit.edu \\ ${ }^{2}$ School of Information Sciences and Technology \\ Information Sciences and Technology Building \\ Pennsylvania State University \\ University Park, PA 16802 \\ rocker@ist.psu.edu
}

\begin{abstract}
Organizations in today's global economy face continual pressures to remain responsive to changes in the competitive marketplace. One way that firms have adapted to these pressures is to use web-based communication technologies to support virtual project teams. To better understand the effectiveness of these dispersed teams, we have analyzed the transcripts of eight virtual design teams composed of graduate students in information systems. Using a coding scheme based on design rationale concepts, we compare and contrast the communication activities of high and low performing virtual teams working on the early stages of software design.
\end{abstract}

Our results suggest that the high performing virtual teams significantly out-communicated the low performing virtual teams. High performing teams communicated more regarding design alternatives. They also spent considerably more effort summarizing their work and discussing the write-up of the final design deliverable. The leaders of high performance teams had more communication content than leaders of low performing teams.
Key Words: Virtual design teams, communication, team performance, virtual team leadership

\section{INTRODUCTION}

Organizations in today's global economy face continual pressures to remain responsive to changes in the competitive marketplace. This new global business environment is creating increased time compression in product development and software design cycles and is forcing organizations to use more off-shore subcontracting [45]. These companies are turning to virtual teams because of the promise of flexibility, responsiveness, lower cost, and improved resource utilization - all necessary to meet the ever changing task environments in highly turbulent and dynamic business environments [19].

Virtual teams are increasingly being used in new product development [44] and in software development, particularly software design. For example, one research team [5] described how a virtual, global engineering team was able to design and prototype a complex device (i.e., an optical seeker used in missiles) in an 
unprecedented six months. The team accomplished the majority of work using asynchronous communication technologies.

Virtual teams link people and activities across organizational boundaries. They tend to be ad-hoc, where members are assigned to the team for the duration of a project and bring together divergent perspectives, skills and talents of people to accomplish organizational objectives such as complex problem solving. These virtual teams are composed of geographically dispersed knowledge workers who communicate [22] and collaborate using advanced information and communication technology [42] [50] such as email or computer conferencing, to complete projects [19].

As the ability to communicate electronically increases the number of relationships that the team can foster due to its ability to work in a global context also increases. Not all teams will be virtual, organizations will still utilize face-to-face teams (i.e. juries, legislative bodies) and combinations of virtual and face-to-face [26]. Leenders [25] suggests that the level of virtuality for some projects will vary over the lifespan of the project, and thus it is necessary to consider virtuality as a continuum.

Virtual teams may have a series of face-to-face meetings, but as Townsend [49] suggests, they may rarely meet. Contrary to this, several authors suggest that a true virtual team will be scarce [12] [13] [25]. They are temporary structures that are designed to accomplish a specific task.

Virtual teams have become the instruments that organizations use to deal with activities and challenges that cross time zones, physical boundaries, and cultures as well as organizational contexts [20]. Thus, virtual teams, supported by communication and information technologies, have emerged as a new organizational structure.

There have been many studies which have compared face-to-face teams with virtual teams or distributed teams [29] [30] [31] [44]. Schmidt [44] compared virtual teams to face-to-face new product development teams. The results suggest that the virtual teams made more effective decisions than the face-to-face teams.

Ocker [30] [31] and Schmidt [44] suggest that the asynchronous computer - mediated - communication technology provided vital support to the virtual teams in terms of information exchange, recall and processing.
In another recent study on virtual teams [43] communication was stressed as an important part of team development and project execution. However, none of these studies evaluated task communication and effectiveness.

Tannenbaum [47] developed a complex team effectiveness models which includes task characteristics, work structures, individual characteristics, and team characteristics as input; team process and team interventions as throughput; and team change, team performance and individual changes as output. The bulk of the research on team effectiveness has focused on the input characteristics and on team interventions such as training and team building [14] [47]. The team processes (coordination, communication, decision making, and problem solving) have received considerable attention [10] [39] [40] however, as Hollingshead and McGrath [17] suggest how the team process is distributed over time and over the group's functions, modes, and tasks have been ignored. One study [46] investigated a way to improve a virtual team's communication in the early stages of group development using a dialogue technique. The technique included three phases: 1) introduction, where the team members introduce themselves; 2) group norm and procedure development, where they list what is considered good practices; and 3) shared understanding, where shared mental models are developed. The results suggest that the dialogue technique appears to give virtual teams a head start that they are able to maintain over time. However, there have been no studies that have investigated the task related communication of virtual teams and what makes one team "better" than another team. In other words, what distinguishes a high performing virtual team from a low performing virtual team in terms of task related communications? An exception to this is a recent study by Carte [3] who reported that the high performing virtual teams generated more messages than lower performing teams. This study was more interested in leadership behaviors and did not analyze the task communication patterns.

Qureshi, Liu and Vogel [40] reported that positive communication can bring about a shared understanding and effective collaboration. The lack of mutual knowledge and shared understanding among team members can hamper communication leading to poor decision quality and performance.

Within the domain of software development, we carried out a series of three experiments comparing teams working on the early stages of software design. Results of our previous studies indicate that these virtual 
design teams outperformed face-to-face teams in terms of both the quality of the resulting design and creativity of the design [29] [30] [31]. These studies reported results only pertaining to outcome measures; they did not report on aspects of the actual design discussions (task related communication) that produced the results.

The research presented in this paper extends our prior research by delving into the heretofore black box of the communication that groups engaged in to achieve their outcomes. Specifically, this paper presents results of a detailed content analysis of the computer-based communication transcripts for eight experimental virtual design teams: four high-performing virtual design teams are compared to four low-performing virtual design teams. These teams accomplished either all or the vast majority of their work by communicating virtually using a web-based computer conferencing system.

This paper presents results of an analysis designed to answer three specific questions.

1. Do high and low performing virtual design teams differ in terms of the number of communication messages and message length?

2. Do high and low performing teams differ in the content of their communications?

3. Do the leaders of the high and low performing team account for a greater difference in the number of communication messages and message lengths relative to the teams (the ratio of the leaders to the total team)?

\section{HYPOTHESIS DEVELOPMENT}

\subsection{THEORY - DISTRIBUTED COGNITION- INFORMATION PROCESSING}

Group information processing is the degree to which information, ideas, or cognitive processes are shared among the team members and how this sharing of this information affects both individual and team outcomes [6] [16]. This distributed cognition-information processing theory further suggests that sharing relates to a process activity that takes place within team members' working memory leading to a modification of shared knowledge. In virtual teams the information is the messages and their content. The sharing through distributed cognition is the assimilation, combining and understanding of the shared knowledge which leads to new knowledge or knowledge presented in a new way.

The distributed cognition theory [16] provides a basic framework for how teams work. Each team member brings to each activity a network of ideas representing the individual's prior knowledge that is relevant to the task. As the activities continue members of the team share some of their ideas about the task and they process ideas shared by others. As these and other activities proceed the team may construct artifacts (models, diagrams, reports) of their interaction and develop a shared understanding. A leader (assigned or emergent) may monitor and comment on the team's performance further enabling the sharing of information. Thus, the distributed cognition theory suggest that team performance is the interaction of team member's ideas, the sharing and processing of these ideas, and a leader process of commenting and processing of the shared information. Further support for the distributed cognition theory comes from the experimental research, teams that developed a better shared model performed better than teams that did not [40] [46].

\subsection{Number OF COMMUNiCATION MeSSAGES AND MESSAGe LENGTH}

Most research involving computer supported teams focus on simple relationships between input and outcome variables [9] [10] [27]. Hackman and Morris [15] suggest that the key to understanding team effectiveness is to focus on the manner in which team members interact when working on a task. They view the team interaction process as a mediator of team inputoutput (i.e. performance) relationships. These interactions (i.e. communications, messages, comments, etc) include all observable interpersonal behavior occurring between two arbitrary points in time. Furthermore, observable team effectiveness can be influenced by affecting the coordination of the efforts of individual group members and by affecting the level of effort group members choose to expend working on the group task.

The research on team performance has primarily focused on how to improve performance [4] [24] and not on determining the salient differences between high and low performing teams. However, one study on face-toface hospital teams [37] reported that there are differences in communication frequencies between high and low performance teams. Basically, high performing teams have significantly more communication in the form of telephone calls, email, and informal discussions. Furthermore, a study of cross-functional project teams found that there were differences in communication volume associated with varying levels of performance [24]. They also suggested that there is a curvilinear relationship with regards to performance with email and face-to-face communication. Email under heavy frequency and quantity degrades performance due to search and storing anomalies. The authors argue that 
when more frequent face-to-face communication took place (to the point of information overload) it indicated either confusion or conflict within the team about project goals, thus lowering performance Carte, Chidambaram, and Becker [3] reported that the high performing virtual teams generated more messages than lower performing teams.

Based on these findings the following hypothesis is presented pertaining to the number of messages and length of the message.

H1: High performing virtual teams will have a greater number of messages and have messages of a longer length (measured by the number of lines in each message) compared to low performing virtual teams.

\subsection{Message Content}

Olson et al. [32] carried out a field study that analyzed ten traditional face-to-face design meetings from four projects in two organizations. These design teams were working on the early stage of software design where small teams of software engineers discussed how to design systems which would be built later, usually by others. Forty percent of the meeting time was spent discussing design, while 30 percent was spent assessing the teams' progress through walkthroughs and summaries. Coordination activities accounted for 20 percent of the work effort. Although the investigators did not measure performance of the design teams, these teams were from two well-respected firms in the area of software development and may be considered to be high performing teams. These team's communication profiles could be considered as a benchmark for how high performing teams design software.

In an effort to improve the effectiveness of design teams a study was conducted with and without the support of communication technology [33]. In essence they created high and low performing teams by providing one set of teams with software. Results suggested that the teams using the software had higher quality designs but fewer design ideas. In terms of design activities, the unsupported teams had a different design profile (communication pattern on alternatives, clarifications and other design issues) than the supported teams. From these findings Olson et al., [32]; Olson et al., [33] we speculate that high and low performing teams will differ in the content of the communications they exchange. It is hypothesized that:

H2: High performing virtual teams will have a different profile of communication (message) content compared to low performing teams.

\subsection{LEADERSHIP}

The presence or absence of leadership can have an effect in a virtual environment [1]. From Hackman and Morris's [15] point of view, leadership affects coordination. Leadership has the potential to interact with the communication and information technology features to effect changes in group processes and outcomes [11]. In this respect, leaders create involvement by creating straw polls, listening to feedback, synthesizing them and incorporating the feedback into written documents and summaries, accessible to all team members [21]. Thamhain [48] suggests that effective project leaders are social architects who understand what coordination is and foster a climate of active participation. Edmondson et al. [7] further suggests that effective teams have effective leaders who actively facilitate the sharing of specific information. Griffith and Neale [12] suggest that there is a positive relationship between group performance and additional managerial efforts (e.g. leadership behaviors focused on group task, procedural and social/relational processes). Yoo and Alavi [51] suggest that emergent leaders send more and longer messages than their team members. Further, these leaders sent a greater number of task-oriented messages related to logistics and coordination that that of nonleaders. This is further supported in another study [2] which suggests that leaders of innovative (creative) teams engage more in role making behaviors which include finding ways to increase communication and synergy. Carte, et al. [3] suggests that there is a positive correlation between leader involvement and performance. They further suggest that leadership behavior type is producer/monitor which is a coordinating type of behavior. Thus, it is hypothesized that:

H3: The leaders of high performing teams will have a greater number of messages and longer messages compared to the leaders of low performing virtual teams.

H4: The leaders of high performing teams with have a different pattern of communication that that of the leaders of the low performing teams.

H5: The leaders of the high performing teams will summarize the communication to a greater extend than the leaders of the low performing teams.

\section{MeTHOD}

The research hypotheses were tested by analyzing the computer conferencing transcripts of the highest and lowest performing virtual design teams from an experiment [29] by means of a content coding 
classification scheme developed by Olson et al. [32]. These procedures are described briefly.

\subsection{Data Sample - the High and low Performing VIRTUAL TEAms}

In this section we will describe the data sample, the basic procedures used to collect that sample and then and how we measured and coded the data. Figure 1 shows the research method for this study. The original study compared three levels of communication mode (asynchronous, combined, and face-to-face) on creativity and quality of virtual teams working on a decision making task. It was noted during the data analysis of this experiment that there was an interesting phenomena taking place some teams outperformed other teams in terms of creativity and quality. Thus, we decided to conduct a more detailed analysis of this observed phenomenon. The two highest and two lowest rated teams in terms of quality and creativity from the original study, in each of the asynchronous and combined conditions were selected. This study then consists of two conditions, high performing teams and low performing teams with a data set consisting of eight groups. The face-to-face condition was not included because there was no electronic or audio transcript or recording of their meetings to analyze. This polar sampling strategy was employed with the intent of making differences between the high and low groups as 'transparently observable' as possible [8] [35]. The sampling approach as well as the number of cases selected in this study is consistent with other research on virtual teams [18] [36].

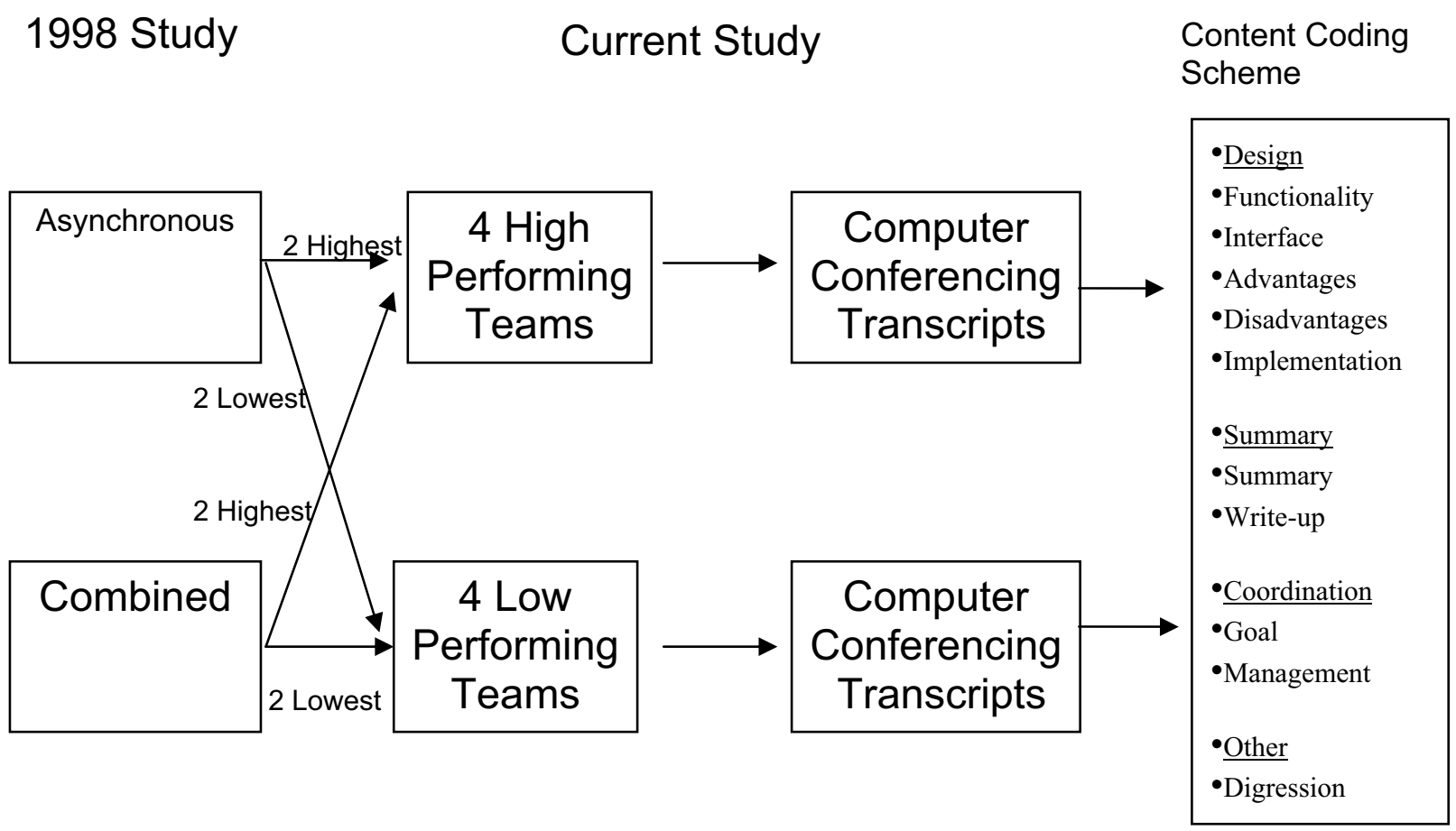

Figure 1: Research Method

As a result of this process, teams 9, 10, 20 and 36 were selected as the high performing teams while teams $8,12,26$, and 33 were chosen as the low performing teams (see Table 1). The quality means were 5.9 for the high performing teams versus 3.5 for the low performing teams. The results on creativity reveled a mean of 6.4 for the high performing teams versus 4.4 for the low performing teams. A t-test analysis showed significant differences in the judges' ratings of quality and creativity between the high performing and low performing teams on both creativity $\left(\mathrm{t}=6.8, \mathrm{t}(6)_{\alpha=0.001}\right)$ and quality $\left(\mathrm{t}=3.3, \mathrm{t}(6)_{\alpha=0.01}\right)$. There were no significant differences within the high and low performing teams in terms of both quality and creativity. These results support our decision to merge teams from the two virtual conditions (i.e., asynchronous and combined) for purposes of analyzing the asynchronous, web-based communications of the high and low performing virtual teams. 
Table 1: Data from Ocker and Fjermestad (1998) Experiment

\begin{tabular}{|l|l|l|l|l|l|l|l|}
\hline $\begin{array}{c}\text { Communication } \\
\text { Mode }\end{array}$ & Team & $\begin{array}{c}\text { Number } \\
\text { of } \\
\text { Subjects }\end{array}$ & $\begin{array}{c}\text { Quality } \\
\text { Rating } \\
(\mathbf{1 - 7 )}\end{array}$ & $\begin{array}{c}\text { Creativity } \\
\text { Rating } \\
(\mathbf{1 - 7 )}\end{array}$ & $\begin{array}{c}\text { Number of } \\
\text { Messages }\end{array}$ & $\begin{array}{c}\text { Message } \\
\text { Length } \\
\text { (No. Lines) }\end{array}$ & $\begin{array}{c}\text { Average } \\
\text { Lines per } \\
\text { Message }\end{array}$ \\
\hline High Teams & & & & & & & \\
\hline Asynchronous & 10 & 6 & 5.5 & 7 & 50 & 442 & 8.8 \\
\hline Asynchronous & 36 & 6 & 6 & 6 & 100 & 842 & 8.4 \\
\hline Combined & 9 & 6 & 6 & 6.5 & 44 & 689 & 15.7 \\
\hline Combined & 20 & 5 & 6 & 6 & 38 & 409 & 10.8 \\
\hline Means & & & 5.9 & 6.4 & 58 & 596 & 10.3 \\
\hline Low Teams & & & & & & & \\
\hline Asynchronous & 12 & 6 & 2.5 & 5 & 34 & 287 & 8.4 \\
\hline Asynchronous & 33 & 6 & 3.5 & 4.5 & 35 & 280 & 8.0 \\
\hline Combined & 8 & 6 & 4 & 4 & 48 & 231 & 4.8 \\
\hline Combined & 26 & 5 & 4 & 4 & 62 & 420 & 6.7 \\
\hline Means & & & 3.5 & 4.4 & 45 & 304 & 6.8 \\
\hline
\end{tabular}

\subsection{Procedures: Content Coding Scheme}

Following from Figure 1, the electronic transcripts of the virtual teams were analyzed for differences in content of communications using a detailed coding scheme [32]. They based their coding scheme on an analysis of the communication of design teams and incorporated design rationale concepts [28] as well as group management activities [38].

Their primary focus was on the problem solving aspects of design, which they viewed as a form of argumentation. Various design issues are raised; for each issue, alternatives are presented and discussed. Criteria are then used to decide upon an alternative. Coordination activities related to organizing the work of team members fall into goal, project and meeting management categories. Other recurring categories include summaries, walkthroughs and digressions. Olson et al. [32] also used a category called clarification to code the explanation of ideas. Finally, they used a category called other to capture those comments that did not fit into any other category.

For ease of comparison and to help clarify relationships among the coded data, we created four composite categories from the eleven previously described coding categories: design, summary, coordination, and other. (These are comparable to composite categories used in the Olson et al. [32] coding scheme.) The design composite category consists of the summation of the coding categories of functionality, interface, advantages, disadvantages and implementation. The summary composite category consists of the summation of the summary and write-up coding categories. The coordination composite category consists of the goal and management coding categories, while the other composite category is the summation of the digression and other coding categories. Also, since we were coding the transcripts resulting from asynchronous discussions, we did not use the meeting management category, but rather, coded all statements having to do with team management into one general management category. Our teams did not participate in walkthroughs per se, but in a similar fashion to the Olson et al. [32] design teams, generated segments of their team report for other team members to review. Therefore, we replaced their walkthrough category with the write-up category.

The second author modified and refined the coding scheme as described above by coding the transcripts of two teams. Two research assistants were trained to use the coding scheme. They also coded the same two teams as the second author. Together, the two research assistants met with the second author to compare their individual coding sheets for each team. Differences in coding were discussed until consensus was reached. The two research assistants then coded the remaining groups, meeting weekly to discuss the coding results of each group and to resolve differences. The coding scheme proved precise and relatively easy to use. Basically $100 \%$ agreement was reached; there were a few minor discrepancies when comparing their individual coding sheets for each group, all resolved to $100 \%$ agreement.

\subsection{Measurement: Number of Communication Messages and Message Length}

The dependent variables examined in this study were designed to measure the constructs of the number of messages and the message length. The communication measures include the number of messages sent by each virtual team, the length of these messages as measured by the number of lines and the 
ratio of lines per message. Based upon a detailed analysis of over 200 experiments [10] these dependent variables are measures of effectiveness in a sub-category of communication. For leadership, the measure of the communication construct is the ratio in percentage form of the leader's frequency and quantity of communication to that of the total teams'. The content of communication is the number of comments in each of the communication categories as defined above. The leader's profile is the ratio in percentage form of the leader's quantity of communication to that of the total teams' by category.

\subsection{METHODS FROM OCKER AND FJERMESTAD (1998)}

3.4.1. SUBJECTS: Subjects consisted of graduate students in computer science or information systems at the New Jersey Institute of Technology. For their participation, all subjects received course credit. The majority of subjects had course work and/or job experience directly relevant to systems design. There were no significant differences in age, work experience or computer experience. Team size ranged from 4 to 7 persons. Subjects were scheduled to meet based on availability for scheduled sessions and randomly assigned to a treatment condition.

3.4.2. Treatment Conditions and Task: All teams worked for a two-week period to produce a written report describing the requirements and high-level design for a Computerized Post Office [33]. The independent variable was communication mode with three levels (asynchronous, combined, and face-to-face). One set of virtual teams, which we refer to as the asynchronous teams, were instructed to work entirely asynchronously while a second set of teams, which we call combined, had a face-to-face meeting at the beginning and end of the experiment ( 1 and $1 / 2$ hours, each) and were instructed to communicate between these two meetings solely through asynchronous means. The third set was face-to-face teams which met at the beginning of the experiment for 1 and $1 / 2$ hours and again at the end of the experiment. This set of teams was not permitted to have any communication at all between meetings. All groups had a leader who volunteered for the role at the end of the training session, sometimes with encouragement from the facilitator. The leaders were informed that they could delegate assignments to other team members provided that other team members agreed. Each leader was responsible for ensuring that his/her group submitted a formal report at the end of the two-week experimental time period.

3.4.3. Procedures: The combined and asynchronous teams were instructed to communicate electronically using a computer conferencing system called Web-EIES developed at the New Jersey Institute of Technology.
Web-EIES is designed to support asynchronous communication through a world-wide-web interface; there are no "chat" facilities (see [29] [30]). An electronic transcript was collected from each virtual team.

In order to evaluate the effectiveness of the teams, a panel of expert judges rated each team's design report, using a seven-point scale, in terms of both its overall quality of design solution as well as the level of creativity displayed in the solution. A total of 8 asynchronous teams and 11 combined teams were included in the original study. Overall, in terms of creativity, asynchronous teams were rated significantly higher than combined teams (5.88 vs. 5.18, $\mathrm{p}=.02$ ). However, concerning quality, no significant differences were found between the asynchronous and combined teams ( 4.43 vs. $4.82, \mathrm{p}=.269$ ).

\section{Results}

Results of analyses are presented at the team level. (The high performing and low performing teams were equivalent in that groups in both conditions consisted of three teams with six members and one team with five members). In order to test the hypotheses concerning differences between high and low virtual teams, a t-test statistic was used. Effect size was also computed. For this study we used Eta-squared [23] [41] which can range from 0 to 1 and represents the proportion of the variance in the dependent variable that is explained by the independent variable. Results are presented for both the composite categories (design, summary, coordination, and other; as described below, see distributions of comment lines) as well as the eleven individual design activities.

\subsection{Number of Messages and Message Length}

Table 2 shows the results of t-tests and effect sizes comparing high and low teams on these measures. Significant results are revealed from the statistical measures for number of messages $(t=7.8, \mathrm{df}=6, \mathrm{p}=$ $0.001)$, message length-number of lines $(t=6.1, d f=6, p$ $=0.001)$ and lines per message $(\mathrm{t}=2.8, \mathrm{df}=6, \mathrm{p}=$ $0.05)$. Effect size for all three dependent variables is at the moderate to strong level $\left(\mathrm{Eta}^{2}=0.88,0.82,0.49\right.$, respectively). These results support hypothesis H1 which suggests that high performing virtual teams do have a greater number of messages (58), longer message length (596), and more lines per message (10.9) than low performing virtual teams, 45, 304, and 6.9, respectively. The effect size results also suggest that even with a small sample these results explain a large portion of the variance and should be taken seriously. 
Table 2: T-test Results- Mean Number of Messages, Message Length and Lines per Message

\begin{tabular}{|c|c|c|c|c|}
\hline Measure & $\begin{array}{c}\text { Mean } \\
\text { High Performing } \\
\text { Teams } \\
\text { (Std) }\end{array}$ & $\begin{array}{c}\text { Mean } \\
\text { Low Performing } \\
\text { Teams } \\
\text { (Std) }\end{array}$ & t-statistic & $\begin{array}{c}\text { Effect Size } \\
\text { Eta-Squared }\end{array}$ \\
\hline $\begin{array}{c}\text { Number of } \\
\text { Messages }\end{array}$ & $58(28)$ & $45(13)$ & $7.8^{* *}$ & 0.88 \\
\hline $\begin{array}{c}\text { Message } \\
\text { Length } \\
\text { (Lines) }\end{array}$ & $596(211)$ & $304(80)$ & $6.1^{* *}$ & 0.82 \\
\hline $\begin{array}{c}\text { Lines per } \\
\text { Message }\end{array}$ & $10.9(3.5)$ & & $2.8^{+}$ & 0.49 \\
\hline$* *$ significant at $\alpha=0.001 ; \mathrm{t}(6)_{\alpha=001}$ where $\mathrm{t}_{\text {crit }}=5.2$ & & & \\
$+=$ significant at $\alpha=0.05 ; \mathrm{t}(6)_{\alpha=05}$ where $\mathrm{t}_{\text {crit }}=1.9$ &
\end{tabular}

\subsection{Message Content}

Table 3 shows the results of t-tests and size effects for each composite category, based on the message length. The results show that design and summary composite categories of the high performing virtual design teams had a significantly greater message length (number of lines). The high performing virtual teams had more than twice as many message lines of communication in the design category as the low performing virtual teams ( 467 vs. $206, t=8.8, d f=6, p$
$=0.01)$. In terms of the summary category, the low performing virtual teams did not have any messages at all. The high performing teams had a mean of 243 lines of communication versus 2 lines of communication for the low performing teams. $(\mathrm{t}=2.7, \mathrm{df}=6, \mathrm{p}=0.05)$. The effect sizes were also high to moderate $\left(\mathrm{Eta}^{2}=0.90\right.$ and 0.49 , respectively). There were no significant differences between the high and low performing virtual teams for the coordination and 'other' composite categories of communication

Table 3: T-Test Results per Composite Category using Mean Message Length (Number of Lines)

\begin{tabular}{|l|c|c|c|c|}
\hline \multicolumn{1}{|c|}{ Measure } & $\begin{array}{c}\text { Mean } \\
\text { High Performing } \\
\text { Teams } \\
\text { (Std) }\end{array}$ & $\begin{array}{c}\text { Mean } \\
\text { Low Performing } \\
\text { Teams } \\
\text { (Std) }\end{array}$ & t-statistic & $\begin{array}{c}\text { Effect Size } \\
\text { Eta-Squared }\end{array}$ \\
\hline Design & $467(118)$ & $206(124)$ & $8.8^{*}$ & 0.90 \\
\hline Summary & $243(104)$ & $2(2)$ & $2.7+$ & 0.47 \\
\hline Coordination & $64(14.7)$ & $39(13.2)$ & Ns & $\sim$ \\
\hline Other & $41(20.6)$ & $41(12.5)$ & Ns & $\sim$ \\
\hline
\end{tabular}

$=$ significant at $\alpha=0.01 ; \mathrm{t}(6)_{\alpha=.01}$ where $\mathrm{t}_{\text {crit }}=3.14$

$+=$ significant at $\alpha=0.05 ; \mathrm{t}(6)_{\alpha=05}$ where $\mathrm{t}_{\text {crit }}=1.9$

Table 4 breaks down the composite communication category of design into content and type. Concerning the former, high performing teams generated significantly more communication regarding the functionality $(\mathrm{t}=$ 7.0, $\mathrm{df}=6, \mathrm{p}=0.001)$, interface design $(\mathrm{t}=3.9, \mathrm{df}=6, \mathrm{p}$ $=0.01)$, and implementation $(\mathrm{t}=4.7, \mathrm{df}=6, \mathrm{p}=0.01)$ of the CPO than did the low performing teams. Effect size was also strong for these dependent variables $\left(\mathrm{Eta}^{2}=\right.$ $0.86,0.65$, and 0.73 , respectively). Furthermore, in terms of design type, the high performance virtual teams.communicated significantly more clarifications $(\mathrm{t}=4.5, \mathrm{df}=6, \mathrm{p}=0.01)$ than the low performing teams. The effect size was also strong for this variable $\left(\mathrm{Eta}^{2}=\right.$ 0.71). Even though the high performing teams had a greater message length (number of lines) on the other content (advantages and disadvantages) and type of communications (alternatives, criterion, and clarifications) they were no significant differences. These differences in communication content provide support for hypothesis $\mathrm{H} 2$. 
Table 4: T-test Results for Content and Type of Design Communication Using Mean Message Length (Number of Lines)

\begin{tabular}{|c|c|c|c|c|}
\hline $\begin{array}{c}\text { Design } \\
\text { Communication } \\
\end{array}$ & $\begin{array}{c}\text { Mean } \\
\text { High Performing } \\
\text { Teams } \\
\text { (Std) } \\
\end{array}$ & $\begin{array}{c}\text { Mean } \\
\text { Low Performing } \\
\text { Teams } \\
\text { (Std) } \\
\end{array}$ & t-statistic & $\begin{array}{c}\text { Effect Size } \\
\text { Eta-Squared }\end{array}$ \\
\hline \multicolumn{5}{|l|}{ Content: } \\
\hline Functionality & $177(38)$ & $86(35.4)$ & $7.0 * *$ & 0.86 \\
\hline Interface & $91(13)$ & $52(33)$ & $3.9^{*}$ & 0.65 \\
\hline Implementation & $86(43.4)$ & $26(19.7)$ & $4.7^{*}$ & 0.73 \\
\hline Advantages & $24.5(12.7$ & $16.5(7.9)$ & $\mathrm{Ns}$ & $\sim$ \\
\hline Disadvantages & $11.3(6 . .6))$ & $12.8(4.4)$ & Ns & $\sim$ \\
\hline \multicolumn{5}{|l|}{ Type: } \\
\hline Alternatives & $172(38.8)$ & $172(39.2)$ & $\mathrm{Ns}$ & $\sim$ \\
\hline Criterion & $50(39.4)$ & $29(18.1)$ & $\mathrm{Ns}$ & $\sim$ \\
\hline Clarifications & $21.5(7.7)$ & $9(8.5)$ & $4.5^{*}$ & 0.71 \\
\hline
\end{tabular}

$* \quad=$ significant at $\alpha=0.01 ; \mathrm{t}(6)_{\alpha=.01}$ where $\mathrm{t}_{\text {crit }}=3.14$

$* *=$ significant at $\alpha=0.001 ; \mathrm{t}(6)_{\alpha=.001}$ where $\mathrm{t}_{\text {crit }}=5.2$

\subsection{LEADERSHIP}

Table 5 shows the results of analyses on leaders' communication measured as the ratio (percent) of communication by the team leader relative to that of the total team. The results indicate that there are no significant differences in the percentages of the leaders number of messages relative to the teams number of messages between the high performing teams (36.5) and the low performing teams (27.3) However, the results suggest that the virtual team leader contributed a large portion of communication content, as measured by the ratio of the teams leader's message length (number of lines) relative to the team's message length (number of lines), $43.3 \%$ for the high performing teams to $22.3 \%$ for the low performing teams, $(\mathrm{t}=7.1, \mathrm{df}=6, \mathrm{p}=0.00)$. The effect size is also large $\left(\mathrm{Eta}^{2}=0.89\right)$. The communication profile (Figure 2) shows that the high performing virtual team leaders have a greater (but not significant) percentage of communication in design communication type (alternatives, clarifications, and criterion) than the leaders of the low performance virtual teams. The high performing leaders have a greater percentage of communication in the "Summary" composite category, but not the in the "Design" and "Other" category than the low performance team leaders. This shows support for hypothesis H3 and H4.

Table 5: T-test Results for Team Leaders Using Ratio of Leaders Messages to that of the Team

\begin{tabular}{|c|c|c|c|c|}
\hline Measure & $\begin{array}{c}\text { Mean } \\
\text { High Performing } \\
\text { Teams } \\
\text { (Std) }\end{array}$ & $\begin{array}{c}\text { Mean } \\
\text { Low Performing } \\
\text { Teams } \\
\text { (Std) } \\
\end{array}$ & t-statistic & $\begin{array}{c}\text { Effect Size } \\
\text { Eta-Squared }\end{array}$ \\
\hline $\begin{array}{c}\% \text { Number of } \\
\text { Messages }\end{array}$ & $36.5(9.5)$ & $27.3(19.4)$ & Ns & $\sim$ \\
\hline $\begin{array}{c}\text { \% Message } \\
\text { length } \\
\end{array}$ & $43.3(8.5)$ & $22.3(8.3)$ & $7.1 * *$ & 0.89 \\
\hline $\begin{array}{c}\text { \% Summary } \\
\text { Messages Length } \\
\text { (No.of Lines) }\end{array}$ & $45.9(42.6)$ & 0 & $5.0 *$ & 0.76 \\
\hline
\end{tabular}

$* *=$ significant at $\alpha=0.001 ; \mathrm{t}(6)_{\alpha=001}$ where $\mathrm{t}_{\text {crit }}=5.2$

$*=$ significant at $\alpha=0.05 ; \mathrm{t}(6){ }_{\alpha=05}$ where $\mathrm{t}_{\text {crit }}=3.14$ 


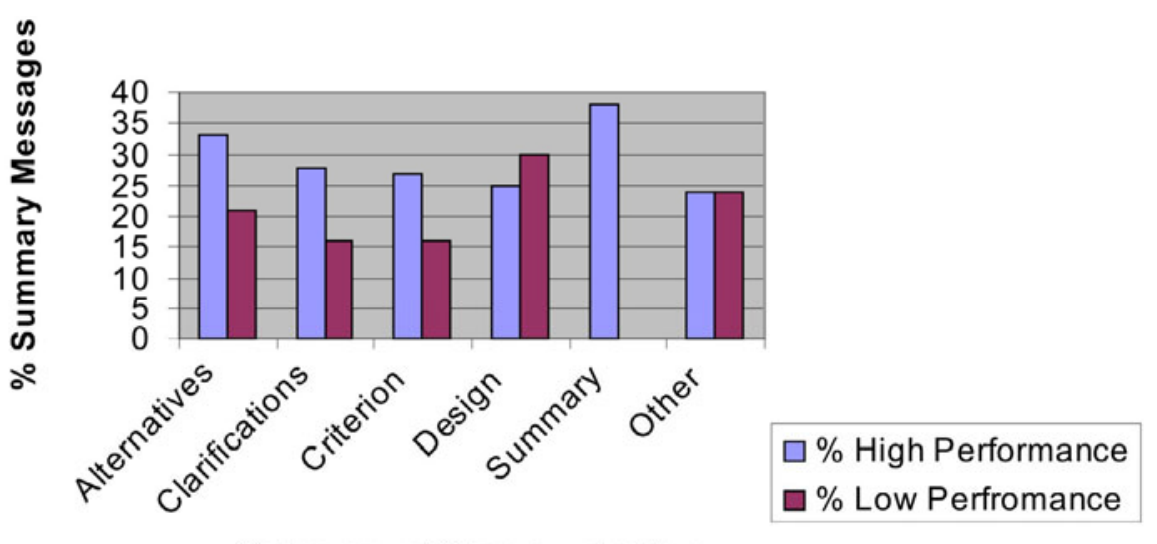

Category of Communication

Figure 2: Team leader's Communication Profile

As shown in Table 5 and Figure 2 the leaders of the high performing virtual teams contributed $45.9 \%$ of the summary message length (in \% of lines) compared to $0 \%$ for the leaders of the low performing virtual design teams $(t=5.0, \mathrm{df}$ $=6, \mathrm{p}=0.05)$. The effect size is also large $\left(\mathrm{Eta}^{2}=0.76\right)$. Thus, hypothesis $\mathrm{H} 5$ is supported.

\section{DISCUSSION, IMPLICATIONS, AND}

\section{LIMITATIONS}

Overall, the high performing virtual design teams differed from their low performing counterparts in terms of number of messages, message length and in the content profile of those messages. The high performing teams had significantly more messages, longer messages as measured by the number of lines) and had a higher message length per message than the low performing teams. Additionally, the leaders of the high teams had more messages and longer messages than the leaders of the low teams. High performing teams communicated more regarding aspects of the design (especially functionality, interface design and implementation considerations). They also spent considerably more messages and message length focused on summarizing their work and discussing the write-up of the report covering the $\mathrm{CPO}$ project design. Our analysis indicates that the high performing teams communicated more than the low performance teams. Simply put, it takes more effort to communicate more, especially in virtual space. The high performance teams not only communicated more, but they communicated regarding key design aspects of the CPO project. Through their increased communication, it is not hard to conceive that they generated a greater number of high quality and creative ideas.
Additionally, and maybe as a consequence of the increased amount of messages, the high performance teams spent time summarizing their work and sharing these summaries with their teammates. This supports the distributed-cognition theory [16] in that the summarization is the development of a shared understanding. Although the high and low performance teams did not differ with respect to the amount of messages concerning team management issues, we expect that the summaries served a coordination function by keeping members apprised of their teammates' ideas and progress. These summaries also appear to be a key when preparing the final design report. Inspection of the transcripts shows that much of the design reports came directly from the text of comments, many of which were summary comments. It is the leaders in the high performing teams that do the summarization. In three of the four high performing teams this was the case. In the fourth team, another team member did the summarization and thus was an emergent leader. In the low performing teams the leaders did not do any summarization at all. Thus, it is plausible that this simple act of summarizing work, coupled with the not-so-simple act of putting forth more effort, were key aspects of the success of the high performance virtual design teams. As several researchers suggest [3] [7] [12] [21] [48] effective teams have effective leaders who actively facilitate the sharing of specific information. This further support the observations from [3] where the leaders of the more effective teams took on the role of monitor and producer In the case of this particular study the leaders are organizing the ideas about the functionality and design of the task for the rest of the team. This summary then becomes the cornerstone of their final report.

These results support and enhance the results reported by Yoo and Alavi [51]. They did not 
investigate high and low performing teams, but reported that leaders (emergent) send more and longer messages than their team members did. Also, Yoo and Alavi [51] suggested that the leaders enacted different roles, those of initiator, scheduler, and integrator. This is supported in this study and further augmented in that there are significant differences between what the leaders do in high versus low performing teams; the leaders of the high performing teams generate more and longer messages, and more importantly act as an integrator by providing summaries of the team work.

Our major contributions in this study are that there are indeed measurable differences (number of messages and message length) between high and low performing virtual teams. The fact that, overall, virtual design teams in our series of experiments [29] [30] [31] have out-performed face-to-face teams in terms of the quality and creativity of the design deliverable, without any structure to the team interaction process, is encouraging. Our results reinforce the overall findings in other technology-mediated research that technology mediation improves performance [10].

A second contribution is that the content of the communication is also different between high and low performing teams. The high performing teams communicate more on the task related issues (functionality, interface, and implementation as well as on summarizing their communications. This is the first study that has shown these differences in the patterns of communication of high and low performing teams.

A third contribution is that this study has shown it is the leaders who do much of the summarization and create the shared intelligence. Yoo and Alavi [51] reported that it was the leaders who carried out a significant portion of load integrating the team members' work into the teams' final deliverables. In this analysis of Ocker and Fjermestad's [29] data, the high performing team leaders are the ones responsible for summarizing the team's ideas and integrating them into the final report. In the low performing teams, it is the absence of this integration by a leader or an emergent leader which leads to a lower performing team as measured by creativity and quality. Without this integration by a leader, the low performing team continues to generate ideas, which does not lead to a cohesive report, in this case the CPO report.

Given the inherent difficulty of design work, the fact that some virtual teams failed miserably should not be surprising. Asking people to accomplish complex collaborative work without the freedom to regularly meet face-to-face is challenging, to say the very least. While some teams perform quite well in virtual situations where no group interaction structure is given, other than providing the work assignment and a deadline, other teams seem to flounder under these circumstances. It seems that in the virtual world, time management skills and structure may be even more important, as it is much easier to ignore team members and your responsibilities when you are working virtually.

A fourth contribution is that this study provides experimental support of the distributed- cognition information processing theory [16]. It is the leaders through summarization or monitoring and producing [3] that aid the teams to produce higher quality and creative outcomes.

\subsection{ImPlications for Professionals ANd MANAGERS}

There are several implications for professionals, managers and software designers. First, managers need to understand the nature of virtual teams and leadership. As Avolio, et al. [1] suggest, we must examine the patterns that emerge overtime interacting with the team, technology and the task. For example, it appears that the low performance teams never completed idea generation; they just keep on brainstorming regarding aspects of the design. On the other hand, the high performance teams entered a summarization phase, which appears to be directly linked to the report writing phase. This matches the results of the Olson et al., [32] where the teams spent $30 \%$ of their time in summaries and walkthroughs. This also supports the leadership literature where teams and leaders find ways to share and facilitate information [12] [13] [25] [51]. Second, leaders need to be aware of the transitions (for instance, from idea generation and brainstorming to building consensus to generating the final deliverable) that teams need to make in order to successfully meet their deadlines. These transitions also have implications for software designers- to design flexible collaborative systems with structures for idea generation, summaries, report writing, and other appropriate areas to help coordinate and organize virtual communication.

\subsection{IMPLICATIONS FOR RESEARCHERS}

This is a preliminary study based on four teams in each condition. Additional studies with at least eight to 10 teams per condition should be run. Furthermore, in order to generalize these findings case and field studies comparing the performance of virtual teams should be run. An additional potential contribution from this research is by carefully integrating some process structure either through leadership or software may help a team to a higher level of performance. The software could either be structure following from or work through artificial intelligence to inform the team to move to the next phase of work [46]. 


\subsection{Limitations}

The results of this study should be interpreted within the context of its limitations. This is a preliminary study with small team sizes. Even though the results are significant and the effect size in general is medium to strong there were only four teams in each condition. As several researchers suggest [12] [13] virtuality is on a continuum. The experiment confined the virtual teams to only one mode of communication. Some teams may have performed better with blended or self selected communication modes. Furthermore, this is fast paced world teams use many different forms any combinations communication including: FtF, chat, video, email, telephone, cell phone, fax.). Several studies are in the pilot mode investigating partially distributed teams selfselecting communication modes.

Another limitation is the use of students as subjects. Even though the students were graduate students, many with full time jobs, the teams may differ from members of virtual teams in actual organizations because they have less experience working in teams and solving organizational tasks.

\section{Acknowledgements}

Partial funding for this research was provided by the National Science Foundation grant 9015236 and the New Jersey Center for Multi-Media Research. Additional support was provided by the Lier Foundation. We would like to thank three outstanding anonymous reviewers for there careful and supportive review of this manuscript. A special thank you is extended to Nicholas C. Romano, Jr. for help with portions of the manuscript. The opinions expressed are those of the authors.

\section{REFERENCES}

[1] B.J. Avolio, S. Kahai, and G.E. Dodge, Eleadership: implications for theory, research, and practice, Leadership Quarterly, 11(4): 615-668, 2001

[2] G. Barczak, and D. Wilmon, Leadership differences in new product development teams, Journal of Product Innovation Management, 6(3): 159-167, 1989.

[3] T.A. Carte, L. Chidambaram, and A. Becker, Emergent leadership in self-managed virtual teams, Group Decision and Negotiation, 15, pages 323-343, 2006.

[4] P. Castka, C.J. Bamber, J.M. Shapre, and P. Belohoubek, Factors affecting successful implementation of high performance teams, Team Performance Management, 7(7/8): 123134, 2001.
[5] M.R. Cutosky, J.M. Tenenbaum, and J.Glicksmant, Madefast: Collaborative engineering over the Internet, Communications of the ACM, 39(9): 78-87, 1996.

[6] S.J. Derry, L.A. DuRussel, and A.M. O'Donnell, Individual and distributed cognition in interdisciplinary teamwork: a developing case study and emerging theory, Educational Psychology Review, 10(1): 25-56, 1998.

[7] A.C. Edmondson, M.A. Roberto, and M.D. Watkins, A dynamic model of top management team effectiveness: managing unstructured task streams, The Leadership Quarterly, 14(3): 297325, 2003.

[8] K.M. Eisenhardt, Building Theories from Case Study Research, Academy of Management Review, 14(4): 532-550, 1989.

[9] J. Fjermestad, An integrated framework for group support systems, Journal of Organizational Computing and Electronic Commerce, 8(2): 83107, 1998 .

[10] J. Fjermestad and S.R. Hiltz, An assessment of group support systems experimental research: Methodology and results, Journal of Management Information Systems, 15(3): 7-149, 1999.

[11] J.F. George, G. Easton, J.F. Nunamaker, and G.B. Northcraft, A study of collaborative group work with and without computer-based support, Information Systems Research, 1(4): 394-415, 1990.

[12] T.L. Griffith, and M.A. Neale, Information processing in traditional, hybrid, and virtual teams: from nascent knowledge to transitive memory, in Research in Organizational Behavior, B. M. Staw and R. I.Sutton (Eds.), Volume 23, pages 379-421, JAI Press, Stamford, 2001.

[13] T.L. Griffith, J.E. Sawyer, and M.A. Neale, Virtualness and knowledge in teams: managing the love triangle of organizations, individuals, and information technology, MIS Quarterly, 27(2): 265-287, 2003.

[14] R.A. Guzzo, Fundamental considerations about work groups, in Handbook of Work Group Psychology, West, M.A., (Ed), John Wiley, \& Sons, West Sussex, England, 1996.

[15] R.J. Hackman and C.G. Morris, Group tasks, group interaction processes and group performance effectiveness: a review and proposed integration, in Advances in Experimental Social Psychology, L. Berkowitz, (Ed.), Academic Press, New York, 1975.

[16] V.B. Hinsz and R.S. Tindale, and D.A. Vollrath, The emerging conceptualization of groups as information processors, Psychology Bulletin, 121(1): 43-64, 1997.

[17] A.B. Hollingshead and J.E. McGrath, Computer-assisted groups: a critical review of the empirical research, in Team Effectiveness and 
Decision Making in Organizations, R.A. Guzzo and E. Salas, (Eds.), Jossey-Bass, San Francisco, 1995.

[18] S.L. Jarvenpaa, K. Knoll, and D.E.Leidner,. Is anybody out there? Antecedents of trust in global virtual teams, Journal of Management Information Systems, 14(4): 29-64, 1998.

[19] S.L. Jarvenpaa and D.E.Leidner, Communication and Trust in Global virtual teams, Organization Science, 10(6): 791-815, 1999.

[20] T. Kayworth and D. Leidner, The global virtual manager: a prescription for success, European Management Journal, 18(2): 183-194, 2000.

[21] K.W. Kerber and A.F. Buono, Leadership challenges in global virtual teams: lessons from the field, S.A.M. Advanced management Journal, 69(4): 4-10, 2004.

[22] S.T. Kinney and R.R. Panko, Project teams: profiles and member perceptions-Implications for group support system research and products, Proceedings of the 29th Hawaii International Conference on System Sciences, 1996.

[23] R.E. Kirk, Experimental design: Procedures for the behavioral sciences, Brooks/Cole Belmont, CA, 1982.

[24] D. Knight, C.C. Durham, and E.A. Lock, The relationship of team goals, incentives, and efficacy to strategic risk, tactical implementation, and performance, Academy of Management Journal, 44(2): 26-338, 2001.

[25] R.T. Leenders, J.M.L. van Engelen, and J. Kratzer. Virtuality, communication, and new product team creativity: a social network perspective, Journal of Engineering Technology Management, 20(1): 69-92, 2003.

[26] M.L. Maznevski and K.M. Chudoba,. Bridging space over time: global virtual team dynamics and effectiveness, Organization Science, 11(5): 473-492, 2000.

[27] J.E. McGrath and A.B. Hollingshead, Groups Interacting with Technology, Sage Publications, CA, 1994.

[28] T.P. Moran and J.M. Carroll, Design rationale: concepts, techniques, and use, Erlbaum Associates, N.J, 1996.

[29] R.J. Ocker and J.Fjermestad, Web-based computer-mediated communication: an experimental investigation comparing three communication modes for determining software requirements, Proceedings of the Thirty-First Annual Hawaii International Conference on Systems Sciences, pages, 88-97, 1998.

[30] R.J. Ocker, .J. Fjermestad, S.R. Hiltz, and K. Johnson, Effects of four modes of group communication on the outcomes of software requirements determination, Journal of Management Information Systems, 15(1): 99-118, 1998.

[31] R.J. Ocker, S.R. Hiltz, M. Turoff, and J. Fjermestad, The effects of distributed group support and process structuring on software requirements development teams, Journal of Management Information Systems, 12(3): 127153, 1996

[32] G.M. Olson, J.S. Olson, M. Carter, and M. Storrosten,. Small group design meetings: an analysis of collaboration, Human Computer Interaction, 7, pages, 347-374, 1992.

[33] J.S. Olson, G.M. Olson, M. Storrosten, and M. Carter, Groupwork close up: a comparison of the group design process with and without a simple group editor, ACM Transactions on Information Systems, 11(4): 321-348, 1993.

[34] R.R. Patrashkova-Volzdoska, S.A. McComb, and S.G. Green, Examining a curvilinear relationship between communication frequency and team performance in cross-functional project teams, IEEE Transactions on Engineering Management, 50(3): 262-269, 2003.

[35] A. Pettigrew, Longitudinal field research on change: Theory and practice, National Science Foundation Conference on Longitudinal Research Methods in Organizations, Austin, TX, 1988.

[36] G. Piccoli and B.Ives, Trust and the unintended effects of behavior control in virtual teams, MIS Quarterly, 27(3): 365-395, 2003.

[37] M.B. Pinto and J.K. Pinto, Project team communication and cross-functional cooperation in new program development, Journal of Product Innovation Management, 7(3): 200-212, 1990.

[38] M.S. Poole and R.Y. Hirokawa, Communication and Group Decision Making, Sage, New York, 1986.

[39] G.P. Powell and B. Ives. Virtual teams: a review of current literature and directions for future research, The Data Base for Advances in Information Systems, 35(1): 6-37, 2004.

[40] S. Qureshi, M. Liu, and D. Vogel, The effects of electronic collaboration in distributed project management, Group Decision and Negotiation, 15, pages, 55-75, 2006.

[41] R. Rosenthal and R.L. Rosnow, Essentials of behavioral research: Methods and data analysis, McGraw Hill, New York, 1991.

[42] A.F. Rutkowski, D.R. Vogel, M.V. Genuchten, T.M.A. Bemelmans, and M. Favier, Ecollaboration: the reality of virtuality, IEEE Transactions on Professional Communication, 45(4): 219-230, 2002.

[43] S. Sanker, F. Lau, F., and S. Sanhay, Using an adapted grounded theory approach for inductive theory building about virtual team development, The Data Base for Advances in Information Systems, 32(1): 38-56, 2001.

[44] J.B. Schmidt, M.M. Montoya-Weiss, and A.P. Massey, New product development decisionmaking effectiveness: comparing individuals, face-to-face teams, and virtual teams, Decision Sciences, 32(4): 575-600, 2001. 
[45] T.A. Stewart, Managing in a wired company, Fortune, 130, pages, 44-56, 1994 ..

[46] B.C.Y. Tan, K.K. Wei, W.H. Huang, and G.N. $\mathrm{Ng}$, A dialogue technique to enhance electronic communication in virtual teams, IEEE Transactions on Professional Communication, 43(2): 153-165, 2000.

[47] S.I. Tannenbaum, E. Salas, and J.A. CannonBowers, Promoting team effectiveness, in Handbook of Work Group Psychology, M.A. West, (Ed.), John Wiley, \& Sons, West Sussex, England, 1996.

[48] H.J. Thamkain, Leading technology-based project teams, Engineering Management Journal, 16(2): 35-42, 2004.

[49] A.M. Townsend, S.M. DeMarie, and A.R. Hendrickson, Virtual teams: technology and the workplace of the future, Academy of Management Executive, 2(3): 17-29, 1998.

[50] M.E. Warkentin, L. Sayeed, and R. Hightower, Virtual teams versus face-to-face teams: an exploratory study of a web-based conference system, Decision Sciences, 28(4): 975-996, 1997.

[51] Y. Yoo and M. Alavi, Emergent leadership in virtual teams: what do emergent leaders do? Information and Organization, 14(1): 27-58, 2004. 